\title{
CURVA DE ABSORÇÃo DE ÁGUA EM SEMENTES DE PINHÃO-MANSO (Jatrophas curcas L.) ${ }^{1}$
}

\author{
Tatiane Evencio², Delacyr da Silva Brandão Junior ${ }^{3}$, José Maria Gomes Neves ${ }^{4}$, Antônio de Amorim \\ Brandão ${ }^{5}$, Hélida Mara Magalhães ${ }^{5}$, Cândido Alves da Costa ${ }^{3}$ e Ernane Ronie Martins ${ }^{3}$
}

\begin{abstract}
RESUMO - O presente trabalho teve o objetivo de caracterizar a curva de absorção de água em sementes de pinhão-manso (Jatrophas curcas L.) pelo método teste-padrão, com sementes mantidas em rolo de papel de filtro umedecido em água destilada. O delineamento experimental foi o inteiramente casualizado, em esquema fatorial 2 x 16, sendo 2 classes de sementes (vivas e mortas), com 16 períodos de embebição e 4 repetição de 10 sementes por parcela. E foi realizado o teste de tetrazólio para verificar a não viabilidade das sementes. As sementes de pinhão-manso apresentaram o padrão trifásico de embebição. Onde a fase I foi comum para as sementes vivas e mortas, estendendo-se por 15 horas. Apenas sementes vivas ingressaram na fase II, estendendo-se por 45 horas, sendo compreendida entre 15 até 60 horas de embebição. Somente sementes vivas ingressaram na fase III, após 60 horas de embebição, quando foi possível visualizar a emissão da radícula.
\end{abstract}

Palavras-chave: Jatrophas curcas L., Fases da germinação e Embebição.

\section{CURVE OF WATER ABSORPTION IN SEEDS JATROPHA (Jatropha curcas L.)}

\begin{abstract}
The present study aimed to characterize the water absorption curve in pinhão-manso seeds (Jatrophas curcas L.), for the method test-pattern, with seeds maintained in roll of filter paper humidified in distilled water. The experimental delineation was entirely randomized, in factorial outline $2 \times 16$, being 2 classes of seeds (live and dith), with 16 periods of imbibitions and 4 repetitions of 10 seeds per parcel. In the tetrazolium test was accomplished to verify the non viability of the seeds. The seeds of pinhão-manso presented the three-phase germination pattern of imbibitions. Where the phase I was common for the live and deth seeds, extending for 15 hours. A live seeds just entered in the phase II, extending for 45 hours, being understood among 15 up to 60 hours of imbibition. Only live seeds entered in the phase III, after 60 hours of imbibition, when was possible to visualize the emission of the root..
\end{abstract}

Key words: Jatrophas curcas L., Germination phases and Imbibition.

\section{INTRODUÇÃO}

Apesar de ser espécie conhecida e cultivada desde a época pré-colombiana, o pinhão-manso (Jatropha curcas L.) demanda muitos estudos para a sua domesticação. O interesse por essa oleaginosa tem aumentado devido à sua promissora utilização como matéria-prima na produção do biodiesel. No entanto, ainda não foram estabelecidos regras e padrões para produção, comercialização e avaliação da qualidade das suas sementes no Brasil. A formação de regras e parâmetros para análises e comercialização de sementes é etapa fundamental para a seleção de variedades mais produtivas (SATURNINO et al., 2005).

\footnotetext{
${ }^{1}$ Recebido em 29.06.2008 e aceito para publicação em 16.12.2010.

${ }^{2}$ Laboratório de Análise de Sementes, Instituto de Ciências Agrárias, Universidade Federal de Minas Gerais, Brasil. E-mail: <tatiane.ufmg.2008@hotmail.com.br>.

${ }^{3}$ Instituto de Ciências Agrárias, Universidade Federal de Minas Gerais, Brasil. E-mail: <dsbrandaojr@ufmg.br>, <candido-costa@ufmg.br> e<ernane-martins@ufmg.br>.

${ }^{4}$ Programa de Pós-Graduação, Universidade Federal de Viçosa, UFV, Brasil. E-mail: <josemariauf@yahoo.com.br>.

${ }^{5}$ Programa de Pós-Graduação em Agroecologia pela Universidade Federal de Minas Gerais, Brasil. E-mail: <toniagrick@yahoo.com.br> e <helidamara2000@yahoo.com.br>.
} 
A germinação constitui a fase do ciclo de vida do vegetal que influência diretamente a distribuição das plantas (SOUZA et al., 2007). É um fenômeno biológico que pode ser definido como a retomada do crescimento do embrião, com o subsequente rompimento do tegumento pela radícula (SARAIA, 1998).

A absorção de água pelas sementes, durante o processo de germinação, é fundamental na retomada das atividades metabólicas e segue padrão trifásico na maioria das espécies, onde a primeira fase ocorre de forma rápida, devido à diferença de potencial hídrico, entre a semente e o substrato, tanto para sementes vivas quanto mortas. A embebição é um processo físico, relacionado com as propriedades dos colóides, e ocorre tanto em sementes vivas quanto mortas (MAYER e MAYBER, 1978; COPELAND e MCDONALD, 1995). Já a fase II é caracterizada por redução drástica na velocidade de absorção, marcada pela reativação do metabolismo, com aumento da difusão de solutos para regiões de marcante metabolismo e, principalmente, na região do embrião. A fase III inicia-se com a emissão da raiz; essa fase só ocorre em sementes vivas e não dormentes. Essas três fases formam a curva de absorção de água pela semente (MARCOS FILHO, 2005; BRAD FORD et al., 1995; BEWLEY e BLACK, 1994).

A importância da curva de absorção de água pelas sementes, com suas fases de entrada de água, está relacionada tanto na elucidação do processo germinativo quanto na determinação da duração de tratamentos com reguladores vegetais, condicionamento osmótico e pré-hidratação (CARVALHO e NAKAGAWA, 2000; ALBUQUERQUE et al., 2000; FERREIRA et al., 2006). Portanto, o estudo da curva de absorção de água pelas sementes de pinhão-manso contribuirá para caracterizar seu processo de germinação, auxiliando na padronização dos testes para avaliação da qualidade fisiológica de suas sementes.

Dessa forma, este trabalho foi realizado com o objetivo de caracterização da curva de absorção de água na semente do pinhão-manso.

\section{MATERIAL E MÉTODOS}

Este estudo foi desenvolvido no Laboratório de Análise de Sementes do Instituto de Ciências Agrárias da Universidade Federal de Minas Gerais (LAS/ICA-UFMG), Campus Montes Claros, MG no período de 13 de setembro a 17 de setembro de 2007. As sementes foram extraídas de frutos maduros, oriundas do Município de Janaúba, MG, de colheitas realizadas no corrente ano.

As sementes foram submetidas à análise da qualidade física através do teste de umidade, utilizando o métodopadrão de estufa a $105^{\circ} \pm$ durante 24 horas. E o peso de 1.000 sementes usando oito subamostras de 100 sementes cada teve o resultado expresso em gramas, conforme as Regras para Analise de Sementes (BRASIL, 1992) e germinação (NEVES et al., 2007).

O delineamento experimental foi o inteiramente casualizado, em esquema fatorial 2 X 16, sendo dois lotes de sementes (vivas e mortas) e 16 turnos de embebição, sendo utilizadas quatro repetições de 10 sementes por parcela. Para os tratamentos com as sementes mortas, realizou-se autoclavagem úmida das sementes vivas por período de 20 minutos, temperatura de $121^{\circ} \mathrm{C}$ e pressão constante (FERREIRA et al., 2006). Foi realizado o teste de Malavasi et al. (2001) para verificar a não viabilidade das sementes.

Inicialmente, cada subamostra de 10 sementes vivas e mortas foi pesada (massa inicial) e semeada em papel germitest (sistema rolo) umedecido com água destilada, empregando-se a quantidade de água referente a 2,5 vezes o peso do papel (BRASIL, 1992), Os tratamentos foram instalados em germinador de sementes modelo Mandelsdorf sob regime de luz natural, na temperatura constante de $30^{\circ} \mathrm{C}$. Após intervalos de tempo predeterminados ( $3 \mathrm{em}$ 3 horas no primeiro dia, 6 em 6 horas no segundo dia, 12 em 12 horas no terceiro dia e de 24 horas a partir do quarto dia de embebição), as sementes foram retiradas dos tratamentos, pesadas (massa final) e colocadas em estufa a $105^{\circ} \mathrm{C}\left( \pm 3^{\circ} \mathrm{C}\right)$ por 24 horas, para determinação do grau de umidade (BRASIL, 1992).

O teste tetrazólio foi realizado, nas sementes vivas e mortas, com solução aquosa de 0,5\% de 2,3,5 trifenil de tetrazólio. Retirou-se o eixo embrionário das sementes, vivas e mortas. Os eixos embrionários foram cobertas por 12 horas com solução 0,5\% de 2,3,5 trifenil de tetrazólio e avaliados quanto à viabilidade, com base na sua mudança de coloração (BRASIL, 1992).

Os dados apresentaram distribuição normal por meio de transformação em arco-seno “?(x /100) para a normalização de sua distribuição, de acordo com BARTLETT (1947 citado por LIMA et al., (2006). As análises estatísticas foram realizadas com o auxílio do 
programa Sistema de Análises Estatísticas e Genéticas (SAEG); nas análises de variância, usou-se o Teste F a 5\% de probabilidade. Para o fator quantitativo, foram ajustadas equações de regressão.

\section{RESULTADOS}

Os resultados da determinação do peso de 1.000 sementes o lote foi separado (esta frase está sem sentido) em sementes vivas e mortas de acordo com a metodologia, sendo o peso de 1.000 sementes para as vivas de 720,80 g e para as sementes mortas de 751,70 g.

No teste de tetrazólio, sementes vivas apresentaram 97\% dos eixos embrionários corados com o tetrazólio, evidenciando-se que 3\% dos embriões estavam inviáveis para a germinação e $97 \%$ viáveis para germinar no lote de sementes vivas. Considerando sementes mortas, $100 \%$ dos eixos embrionários não foram corados, evidenciando-se que $100 \%$ dos embriões e, portanto, as sementes não estavam viáveis para germinar. Pelos resultados do teste de tetrazólio foi possível comprovar que o processo de autoclavagem das sementes foi eficiente para a morte das sementes, além de confirmar a elevada qualidade fisiológica (97\% de viabilidade) da subamostra das sementes vivas.

Quanto aos resultados dos graus de umidade das sementes, o das sementes mortas foi superior, inicialmente, ao das sementes vivas. As sementes mortas foram submetidas à autoclavagem úmida, e sua massa de água foi superior à das sementes vivas, possivelmente por terem absorvido água no processo de autoclavagem. A utilização dos períodos de embebição para as determinações de aumento ingresso de água nos tecidos (umidade) e aumento de massa das sementes (peso) ao longo das 96 horas de embebição e as sementes vivas obtiveram valores superiores tanto do peso de água quanto da umidade no final do período de avaliação. No trabalho de Lima et al. (2006) com sementes de Caesalpinia ferrea recém-coletadas, observou-se baixa germinação das sementes, o que se deveu ao baixo ganho de água durante a embebição, demonstrando que as sementes apresentaram dormência tegumentar.

Os valores da umidade nas sementes vivas e mortas não diferenciaram estatisticamente entre 0 e 15 horas de embebição, em que foi caracterizado o fim da primeira fase desse processo (fase I) (Figura 1). Observou-se que não houve diferença estatística em umidade ou massa de água nas sementes nas primeiras 12 horas de embebição, com teor de umidade de $36,0 \%$ para sementes vivas e $34 \%$ para sementes mortas. Segundo Carvalho e Nakagawa (2000) as sementes cotiledonares encerram a fase I quando atingem teores de água entre 35 e 40\%, a partir desses teores seria iniciada a fase II. A duração de cada fase depende de propriedades inerentes às sementes e às condições ambientais (BEWLEY e BLACK, 1994).

Neste trabalho, aproximadamente até as 60 horas em que houve a emissão de radícula foi caracterizado o fim da fase II. Entre as 15e60 horas, puderam ser observados, tanto nas sementes vivas quanto nas mortas, lenta absorção de água e baixo ganho de peso de água, caracterizados pela fase II. Segundo Carvalho e Nakagawa (2000), é uma fase comum em algumas sementes, tanto para as vivas quanto para as mortas, como pôde ser observado no trabalho com sementes vivas e mortas do pinhão-manso. Nas sementes de pinhão-manso, após 60 horas de embebição pôde ser verificada a emissão de radícula nas sementes vivas com umidade de 52,7\% (Figura 1 ) e, a partir das 60 horas, a retomada na absorção de água e ganho no peso de água para as sementes vivas. A última fase da embebição (fase III) foi caracterizada pelo crescimento visível do eixo embrionário, em que a umidade varia entre 50 e $60 \%$ nas sementes cotiledonares e na fase em que a semente volta a respirar e absorver água intensamente. As Figuras 1 e 2 de umidade e massa de água na semente, respectivamente, demonstram a evolução da curva de absorção de água pelas sementes ao longo de 96 horas. Na Figura 1 é possível visualizar as fases de embebição. Nas sementes vivas, a primeira fase dura até as 15 horas, quando há maior crescimento no teor da umidade; a segunda fase dura até 60 horas, quando o aumento de umidade é lento; e a terceira fase após as 60 horas, quando o aumento no teor de umidade é mais acelerado. Por meio da Figura 2,

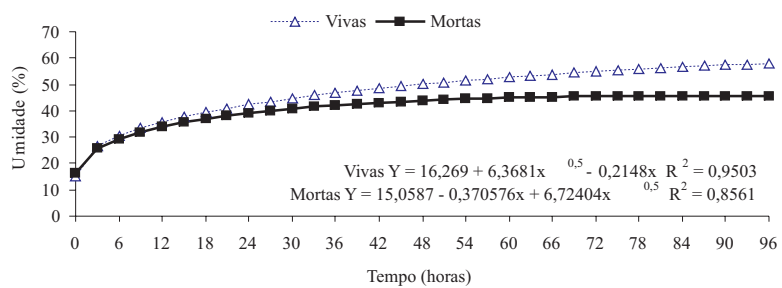

Figura 1 - Grau de umidade (\%) das sementes vivas e mortas do pinhão-manso (Jatropha curcas L.), ao longo de 96 horas.

Figure 1 - Humidity degree (\%) of the live and dith seeds of the pinhão-manso (Jatropha curcas L.), along 96 hours.

Revista Árvore, Viçosa-MG, v.35, n.2, p.193-197, 2011 


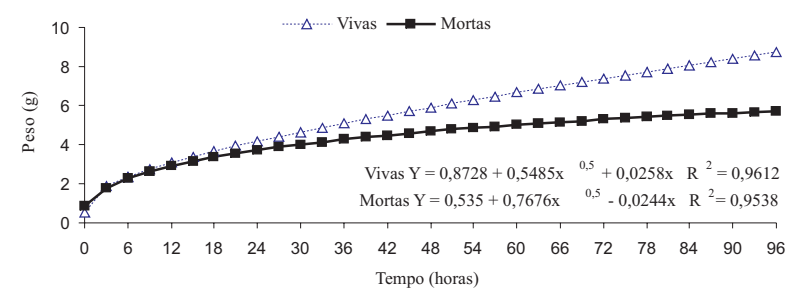

Figura 2 - Massa de água nas sementes vivas e mortas do pinhão-manso (Jatropha curcas L.), ao longo de 96 horas.

Figure 2-Mass of water in the live and dith seeds of the pinhão-manso (Jatropha curcas L.), along 96 hours.

é possível observar aumento linear na quantidade de água nas sementes vivas. Nas últimas 36 horas do trabalho, as sementes vivas aumentaram o ritmo no ganho de peso de água, e as mortas estabilizaram seu ganho de quantidade de água (massa).

\section{CONCLUSÃO}

As sementes de pinhão-manso seguem o padrão trifásico de embebição, sendo:

A fase I foi comum nas sementes vivas e mortas, estendendo-se por 15 horas.

- Apenas sementes vivas ingressaram na fase II, estendendo-se por 45 horas, sendo compreendida entre 15 e 60 horas de embebição.

- Somente sementes vivas ingressaram na fase III, após 60 horas de embebição, quando foi possível visualizar a emissão da radícula.

\section{REFERÊNCIAS}

ALBUQUERQUE, M.C.F.; RODRIGUES, T. DE J.D.; MENDONÇA, E.A.F. Absorção de água por sementes de Crotalaria spectabilis Roth determinada em diferentes temperaturas e disponibilidade hídrica. Revista Brasileira de Sementes, Brasília, v. 22, p. 206-215, 2000.

BARTLETT, M. S. The use of transformations. Biometrics, v .3, p. 39-52, 1947.

BEWLEY, D.D.; BLACK, A.M. Seeds: physiology of development and germination. New York: Plenum, 1994. 445, 4467p.

BRADFORD, K.J. Water relations analysis of seed germination. In: KIGEL, J.; GALILI, G. (Ed.). Seed development and germination. New York: Marcel Decker., 1995. p. 351- 396.
BRASIL. Ministério da Agricultura e Reforma Agrária. Regras para análise de sementes. Brasília, 1992. 365p.

CARVALHO, N.M. \& NAKAGAWA, J. Sementes: ciência, tecnologia e produção. Jaboticabal: Funep, 4.ed. 588p., 2000.

COPELAND, L.O.; McDONALD, M.B. Principles of seed science and technology. 3. ed. New York: Chapman \& Hall, 1995. 409p.

FERREIRA, G; GUIMARÃES, V. F; PINHO, S.Z; OLIVEIRA, M. C; RICHART A, BRAGA, J.F; DIAS, G.B.Curva de absorção de água em sementes de atemoia (Annona cherimola Mill. x Annona squamosa L.) cv. gefner. Revista Brasileira Fruticultura, Jaboticabal - SP, v. 28, n. 1, p. 121-124, Abril, 2006.

LIMA, J. D; ALMEIDA, C.C; DANTAS, V.A.V; SILVA, B.M.DA; MORAES, W. S. Efeito da temperatura e do substrato na germinação de sementes de caesalpinia ferrea mart. ex tul. (leguminosae, caesalpinoideae). Revista Árvore, Viçosa-MG, v.30, n.4, p.513-518, 2006.

MARCOS FILHO, J. 2005. Fisiologia de sementes de plantas cultivadas. Piracicaba: FEALQ,202, 495p.

MAYER, A.M.; MAYBER, A.P. The germination of seeds. 2.ed. Oxford: Pergamon Press, 1978. 192p.

MALAVASI, M. M.; FOGAÇA, C.A.; FOGAÇA, L.; FERREIRA, G. Preparo e coloração de sementes de maracujá-doce (Passiflora alata Dryander) para a avaliação da viabilidade através de teste do tetrazólio. Revista Brasileira de Fruticultura, Campinas, v.23, n.1, p.126-129, 2001.

NEVES, J.M.G; SILVA, H.P; BRANDÃO JUNIOR, D. DA S; MARTINS, E.R. Efeito da remoção do tegumento e da temperatura na germinação de sementes de pinhão-manso (Jatropha curcas L.). In: Congresso Brasileiro de Plantas Oleaginosas, Óleos, Gorduras e Biodiesel, 2007, Varginha. Anais... Lavras: UFLA, p. 1500-1508, 2007.

SARAIA M. L. N. / Doutorado - UFSCar (Depto Botânica). Israel Gomes Vieira / Coordenador do Setor de Sementes - IPEF Gelson Dias Fernandes / Laboratorista (LARGEA/LCF/ESALQ/USP). Informativo Sementes IPEF - Abril 1998. 
SATURNINO, H.M; PACHECO, D.D.; KAKIDA, J.; TOMINAGA, N.; GONÇALVES, N.P. Cultura do pinhão-manso (Jatrofa curcas L.). Informe Agropecuário, Belo Horizonte, v.26, n. 229, p. 44-78,2005.
SOUZA, E. B; PACHECO, M. V; MATOS, V. P; FERREIRA, R. L. C. Germinação de sementes de adenanthera pavonina L. em função de diferentes temperaturas e substratos. Revista Árvore, Viçosa-MG, v.31, n.3, p.437-443, 2007. 
